\title{
PROPOSAL OF KEY FACTORS FOR USER-ORIENTED WEB APPLICATIONS
}

The paper deals with issues regarding the identification of key-factors for a successful creation of a user-oriented web application. Described are methods of identification, sources of information and contents of each category. The categories are Search, Display, Home Page and Navigation. The categories are broken-down into a table form. The paper also presents the results of several web applications testing based on new identified key factors. The testing was performed by the Department of Communications using a sample of web pages.

\section{Introduction}

The aims of the user-oriented application design are to satisfy all its users and to ensure their positive experience while using the application. Achieving these aims requires thorough understanding of the target user group needs. It is necessary to obtain the largest possible amount of information about the users, the tools they use at work, their working environment, as well as their expectations and requirements.

The users never spend more than $50 \%$ of their on-line time with any web application. We can expect that, prior to using our web site, the users have visited several more or less similar sites. Each user is individual in their level of abilities to learn, gain experience and correlations from previous tasks. These characteristics determine the user's vision of how an application should work. Cumulation of users' experiences from their previous Internet work leads to subconscious comparing of the positive and negative characteristics of the web applications visited with the current application. Such cumulation of experiences brings about the user's increased requirements, demands and expectations of web applications. [1]

Procedures leading to the creation of user-oriented applications are referred to as User Centered Design (UCD), a proposal for the user. This approach consists of the steps, methods and tools that facilitate creators the prevention and/or problem-solving, especially in the usability of web application proposal. [8]

\section{Theoretical background to tackle}

User-oriented application is nowhere precisely defined. Many authors cover issues by one expression - usability, which of course covers a number of factors. Usability is also part of ISO 9241 Ergonomic requirements for office work with visual display terminals
(VDTs). ISO 9241-11 definition refers to the origin of usability, which is described by users, their tasks and objectives, environment, equipment, and measuring by criteria of efficiency, performance and satisfaction. However, there is a summary of activities on which it is possible to determine what should be done in a specific situation to ensure the usability. ISO $9241-11$ provides recommendations on how to organize the usability evaluation during development process, which would become a guide or structure for developers. The scheme is flexible and can be universally used as a guide when designing applications. Responsibility for the decision of what usability consists is left up to the creator. [9]

With user-oriented design called user-centered or user-friendly also deals the ISO 13407 standard - human-centred design process for interactive systems standard, which it describes as a multidisciplinary activity. It includes human factors and ergonomics knowledge and techniques to increase efficiency, productivity and user satisfaction [10].

Usability of web applications is a very important factor for ensuring the achievement of their success. Usability issues have to be integrated into their design and development applications. It is necessary to systematically define the requirements for usability, including methods of evaluation.

\section{Identifying key factors for user-oriented web applications}

Alike users' increasing requirements on web applications, the owners' expectations are growing of these applications, since the investment costs of their development increase gradually. The higher cost is induced by increasing complexity of the solution. In order for the web application to provide both the functions expected, and thus bring benefit for its user as well as for its owner, the appli-

\footnotetext{
* Iveta Kremenova, Marian Galovic

Department of Communications, Faculty of Operation and Economics of Transport and Communications, University of Zilina, Slovakia, E-mail: Iveta.Kremenova@fpedas.uniza.sk
} 
cation must meet certain criteria. Obviously, the owner can only benefit from the application if its users are satisfied. We have defined key factors, and identified them based on data and information from the following sources:

- consultations with experts in web application code development,

- consultations with experts in web graphic design,

- consultations with experts in web applicability and accessibility,

- consultations with experts from universities,

- observation of users working with the Internet,

- consultations with various user groups of web applications, and own research.

The first source for proposing the key factors was consultation with experts and analysis of the data and information obtained from the Prague marketing agency GFK Praha [11] The agency performs user tests and evaluates important web-application features with possible critical impact on the application's success with its users. GFK Praha utilizes quantitative research using eye-tracking technique, i.e. observing, recording and evaluating the human eye movement over particular applications and various tasks.

With such tests, the ideal number of tested persons is always crucial for individual tests. According to Jacob Nielsen and Thomas Landauer, the number of undetected problems in case of a test with test persons is as follows:

$$
N\left(1-(1-L)^{n}\right)
$$

where $N$ is the total number of errors in the proposal, $L$ is the number of errors detected by one Test Person (TP) during one test run, and $n$ is the number of test persons (TPs). Empirically attested typical value $L$ is $31 \%$, from which the following graph (Fig. 1) can be derived. [1]

Fig. 1 shows the web application errors detection in dependency on the number of test persons (TPs), where Test Person 1 (TP1) is able to detect $31 \%$ of the errors. TP2 undergoing the same test repeats some of the errors but also detects more errors undetected by TP1. TP 3 repeats the errors made by TP1 and TP2, and hence the number of newly detected errors decreases at a constant value of $L$. The more persons are used for the test; the lower is the contribution by every other person to the total number of detected errors. With five TPs it is possible to detect $85 \%$ of errors.

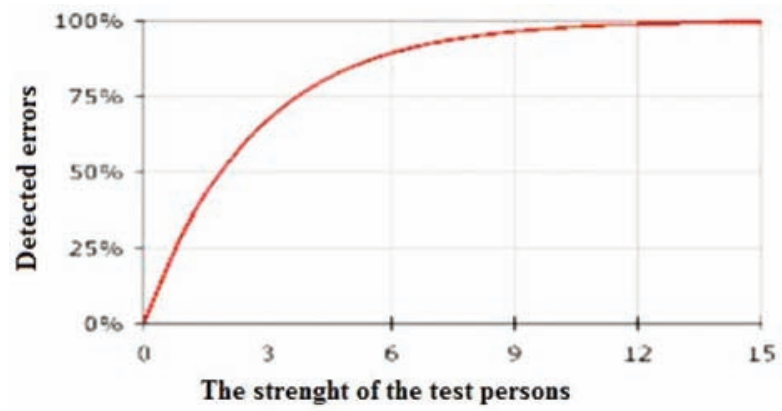

Fig. 1 Dependency of error detection on the number of test persons
Therefore, the use of three to five TPs is suitable for continuous tests, thus ensuring that the test be quick, undemanding and sufficiently efficient. In case of so-called large tests, the number of TPs should be re-considered. However, Fig. 1 proves that no major improvement is brought about by TP numbers larger than 15 .

Agency GFK Praha also performs quantitative research on a group of 8-12 users. Again, Fig. 1 shows that this number is adequate, and any further increase of the TP number would not bring a sufficient increase in the number of detected errors to balance the elevated cost of such testing, as it is time and money intensive.

A different way of testing web applications is to have them tested by an expert in the given field, according to pre-defined criteria, i.e. factors. Based on these factors, it is also possible to identify and propose changes needed for the application improvement. We attempted to propose such criteria on the basis of thorough analyses of multiple web sites.

Another information source for identification and proposal of key factors was verbal communication with users and questionnaire research. The target groups were users with varying grades of education and level of computer and Internet skills. Each participant in the research works with the Internet every day at home and at work or school. Advanced and expert PC and Internet users use various versions of Opera or Mozilla Firefox browsers. Less skilled users prefer the browser under Windows operation system that is Internet Explorer of various versions. Participants in the research identified certain key requirements and errors for a user-oriented web application, and these were completed with the information from web application development experts. Fig. 2 shows 4 categories (groups) of factors and their sequence. The groups include individual factors affecting the given category.

Division of factors in 4 basic groups, based on following assumptions:

- Search - user must be able to find the web application in order to work with it,

- Display - user must see the web application displayed in order to work with it,

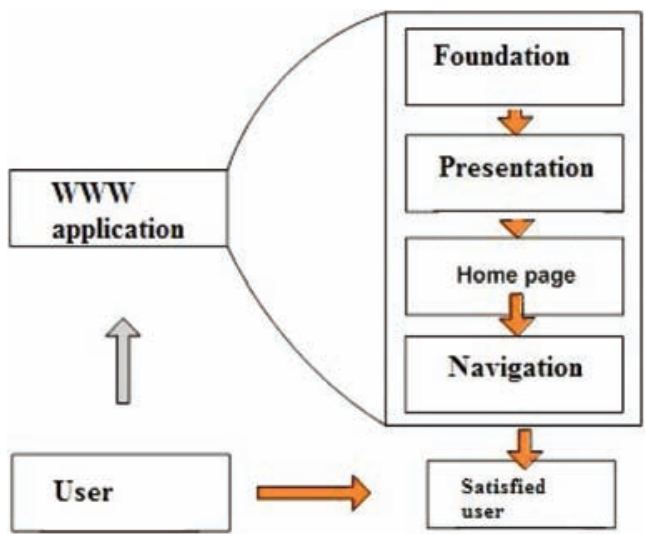

Fig. 2 Basic groups for classification of key factors 
- Home Page - user must be able to use the home page in order to work with the web application without limitations,

- Navigation - user must be able to use a navigation feature in order to work with the web application without limitations.

Fig. 2 also show a graphic representation of the sequence of defined factor groups. Obviously, infringement of individual factors can be critical for the web application success in every phase.

Then, we defined other criteria for web application assessment, which are summarized in Table 1 . The table includes factors considered as crucial, and classified into 4 basic groups.

Proposed key factors include measurable indices with primary or secondary effect on accessibility and on the following user's work with the web application.

Not included are immeasurable factors and factors regarding subjective opinions (judgment) by individual users and their habits. For example, the level of information architecture, complexity of the navigation, and applied colors (even if the contrast is measurable, each user subjectively perceives it differently). For these factors, a user test is more suitable.

Key factors of user-oriented web applications

Table 1

\begin{tabular}{|c|c|c|}
\hline $\begin{array}{l}\text { Cate- } \\
\text { gory }\end{array}$ & Criterion & Partial criterion \\
\hline \multirow{8}{*}{ 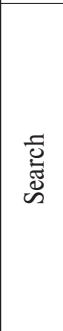 } & Title & \\
\hline & Correct reference nomenclature & \\
\hline & Reference to similar pages & \\
\hline & Proper URL name & \\
\hline & Key words & \\
\hline & Splash page & \\
\hline & Frames & \\
\hline & Google page rank & \\
\hline \multirow{20}{*}{$\begin{array}{l}\frac{\vec{a}}{2} \\
\frac{0}{0} \\
\frac{0}{0}\end{array}$} & \multirow[t]{5}{*}{ Browsers } & IE 6 \\
\hline & & IE 7 \\
\hline & & Mozilla \\
\hline & & Firefox \\
\hline & & Opera \\
\hline & \multirow[t]{2}{*}{ Validity } & HTML/XHTML \\
\hline & & CSS \\
\hline & \multirow[t]{3}{*}{ Display on PDA } & Opera Mobile \\
\hline & & Internet Explorer Mobile \\
\hline & & Mobile page version \\
\hline & Blind friendly - correct document flow & \\
\hline & \multirow[t]{3}{*}{ Resolution } & $800 \times 600$ \\
\hline & & $1024 \times 768$ \\
\hline & & 1280x1024 \\
\hline & \multirow[t]{3}{*}{ Functionality } & JS off \\
\hline & & Flash off \\
\hline & & CSS off \\
\hline & \multicolumn{2}{|l|}{ Print version } \\
\hline & \multicolumn{2}{|l|}{ Correct display of characters } \\
\hline & Home page size & \\
\hline
\end{tabular}

\begin{tabular}{|c|c|c|}
\hline \multirow{9}{*}{ 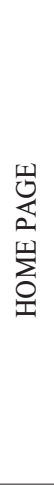 } & $\begin{array}{l}\text { Text alternative of the pictures (alt } \\
\text { tribute) }\end{array}$ & \\
\hline & Text size in IE - large/small & \\
\hline & $\begin{array}{l}\text { No reference opening in new } \\
\text { windows }\end{array}$ & \\
\hline & Error messages with wrong URL & Database \\
\hline & & Server \\
\hline & HELP or FAQ prompt & \\
\hline & Clarity of the Home page focus & \\
\hline & Contact & \\
\hline & $\begin{array}{l}\text { Subpages under HOME PAGE, } \\
\text { within navigation }\end{array}$ & \\
\hline \multirow{11}{*}{ 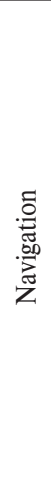 } & Web application map & \\
\hline & Search & present - absent \\
\hline & & diacritics \\
\hline & & internal \\
\hline & & advanced \\
\hline & Use of standard controls & \\
\hline & $\begin{array}{l}\text { Return to HOME PAGE from every } \\
\text { subpage }\end{array}$ & \\
\hline & Navigation bar & \\
\hline & Dictionary of terms & \\
\hline & Operating via keyboard & \\
\hline & Language version & \\
\hline
\end{tabular}

Individual factors and methods of their testing with selected web applications could be further characterized in details. Due to the vast scope of the issue, however, we do not present in this paper all the activities performed. More results are available in the above-mentioned doctorate thesis.

\section{Experimental results of web applications testing}

We can conclude that, based on the key factors identified, we performed tests at the Department of Communication of web applications with various subjects and contents. We tested selected applications by

- universities, ministries, regional capitals, organizations providing economic information, banks, postal administrations, electronic commerce, reporting (on-line newspapers, TV) and on-line information (time tables).

Fig. 3 presents the facts from the testing.

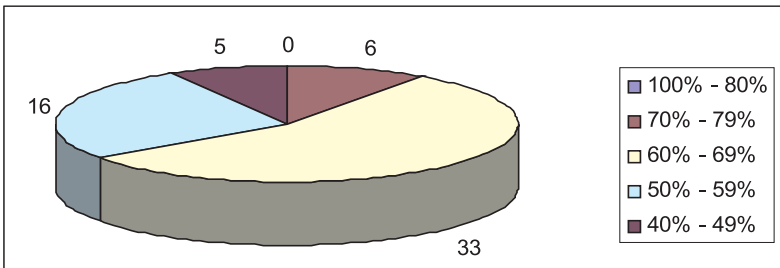

Fig. 3 Graphic representation of web application test results based on the key factors identified 
The test included 60 web applications. None of the tested applications complied with $80 \%-100 \%$ of our identified factors (see Fig. 3). 33 of the tested web applications complied with $60 \%$ $69 \%$ of the factors.

The variety of applications included in the research proves that they are used by various user groups. Therefore, no segmentation can be made in order to modify the key factors according to target groups. The results are not very attractive, as the key factors also included measurable factors not having a subjective characteristic of their assessment. Other drawbacks were detected utilizing a user test. The characteristics of such drawbacks varied substantially depending on individual target group and application. When identifying factors or methods for proposing applications according to selected segment of users, the users from a different segment are always disadvantaged. The subject of this paper, however is not such a segmentation, but rather to show the opportunity to establish the basis for further search, for example, in the field of changing the factors according to individual segments of users.

The test of selected applications with different focus on the defined factors proved that the issue of user-oriented applications is still an open and highly up-to-date one. This is apparent as none of the tested applications complies with all the defined criteria.

\section{Evaluation and conclusions}

Proposal of user-oriented web applications leads to the respect of the standards. The result will increase their accessibility, usabil- ity, compatibility with various platforms, browsers and terminal equipment [6].

In identifying factors or procedures for design applications according to the selected segment of users, will always be disadvantaged the user from another segment. Finally, this article may be said that scientific research has created a basis for further investigation, e.g. in the area of changing factors depending on different segments of users.

Creation of a modern web application does not consist only of designing the look and writing the source code for feature control. The proposal and creation of web applications constitute a complex process that includes multiple various activities. Graphic presentation design is only a part of the whole process chain, although it belongs to the basic and obvious criteria for evaluation of the application by its users. Even the best web application loses its value, if its content is poor or inadequate. Therefore, the content is always the most important feature.

As a field of further exploration we propose designing a methodology for testing factors with subjective influence on particular users of web applications.

\section{References}

[1] NIELSEN, J.: Designing web Usability: The Practice of Simplicity, SoftPress s.r.o. ISBN: 80-86497-27-5, 2002

[2] GALOVIC, M.: Draft Creation to User-oriented Web Applications (in Slovak), Doctoral thesis, EDIS ZU, Zilina, 2008

[3] KREMENOVA, I., ROSTASOVA, M.: Marketing in Services (in Slovak) Marketingovy informacny system EDIS-ZU, Zilina, ISBN 80-8070-358-2, 2005

[4] KREMENOVA, I., KOVACIKOVA, M.: Designing of Technological Processes and Postal Services (in Slovak), EDIS, ZU, Zilina, ISBN 978-80-8070-904-4, 2008.

[5] GALOVIC, M., FABUS, J., KREMENOVA, I., The mistakes of The Web presentations, In: EUNIS 2005: 11th multidisciplinary conference: Manchester, 21.-24. June 2005: University of Manchester, 2005.

[6] GALOVIC, M., KREMENOVA I., FABUS, J.: Ergonomic requirements for web sites, In: EUNIS 2007: 13th multidisciplinary conference: Grenoble:France, 26. - 29. June 2007: Grenoble Universites, 2007.

[7] MURUGESAN, S.; GINIGE, A.: Web Engineering: Introduction and Perspectives, Southern Cross University and University of Western Sydney, Australia, 2005

[8] POWELL, T.: Web Design: The Complete Reference - Second Edition, The McGraw-Hill Companies, Inc. 2002, 0-07-222442-8

[9] ISO 9241 Ergonomic requirements for office work with visual display terminals (VDTs), 1998.

[10] ISO 13407 Human-centred design processes for interactive systems, 1999.

[11] www.gfk.sk/imperia/md/contnt/gfkslovakia/brochures/gfk_temax.maj.pdf. 